\title{
A comparison of the hand hygiene knowledge, beliefs and practices of Greek nursing and medical students
}

TF van de Mortel, MHlthSc. FCN, FRCNA

Faculty of Health \& Applied Sciences, Southern Cross University*,

Lismore, 2480 NSW

Australia

Email: tvandemo@scu.edu.au

$\mathrm{Ph}:$ 61-2-66203305

Fax: 61-2-66203022

E. Apostolopoulou

$\mathrm{PhD}$

A. Prof.,

Faculty of Nursing,

University of Athens\#,

Greece

G. Petrikkos,

$\mathrm{PhD}$

A. Prof.,

Faculty of Medicine\#

\begin{abstract}
Profession influences healthcare workers' hand hygiene $(\mathrm{HH})$ adherence. Greek nursing and medical students were surveyed to determine if there were cross-disciplinary differences in $\mathrm{HH}$ education, assessment, knowledge, beliefs and practices. Nursing students' HH knowledge was significantly higher than that of medical students. Nursing students reported significantly more positive $\mathrm{HH}$ practices and beliefs, and received more $\mathrm{HH}$ education and assessment than medical students. Improving undergraduate HH education may improve graduates' HH knowledge, beliefs and practices.
\end{abstract}




\section{Introduction}

Studies indicate that healthcare workers' adherence to hand hygiene $(\mathrm{HH})$ guidelines is poor $(\sim 40 \%)$ and that physician status is a risk factor for non-adherence. ${ }^{1}$ Disciplinary differences in $\mathrm{HH}$ education and assessment during undergraduate training may impact on graduates' behaviour upon entering the workforce.

Several studies have examined aspects of healthcare students' $\mathrm{HH}$ beliefs or practices. Duration of clinical experience, ${ }^{2,3}$ gender, ${ }^{2}$ the example of mentors, ${ }^{2}$ and perceptions of handwashing benefits, barriers and severity of infectious diseases ${ }^{4}$ significantly influenced self-reported ${ }^{3,4}$ or observed $\mathrm{HH}$ compliance. ${ }^{2}$ Gaps in students' $\mathrm{HH}$ knowledge were also identified by Sangkard ${ }^{4}$ and Mann and Wood. ${ }^{5}$ Sangkard's survey of nursing students' infection control knowledge in relation to Human Immunodeficiency Virus infection included a short handwashing quiz with simple true/false questions. Students' scores on this quiz ranged from 68-71\%. Mann and Wood reported that medical students' average score on a hand hygiene quiz was $52 \%$. However, these studies can't be used to make cross-disciplinary comparisons as the questions on the respective surveys were very different.

Thus the objectives of this study were to:

- $\quad$ determine if the $\mathrm{HH}$ knowledge, beliefs, practices, education and assessment of undergraduate Greek nursing and medical students differed by discipline.

use this information to inform $\mathrm{HH}$ education and assessment in the undergraduate curriculum. 


\section{Methods}

A survey was conducted at the University of Athens, Greece, utilising a translated version of the HH Questionnaire, ${ }^{6}$ which elicited information on demographics, $\mathrm{HH}$ teaching and assessment, and $\mathrm{HH}$ knowledge (13 questions based on the CDC HH guidelines). ${ }^{1}$ The questionnaire also measured $\mathrm{HH}$ beliefs (20 items), practices (14 items), and perceptions of the importance of $\mathrm{HH}$ in the curriculum (3 items) on 5-point Likert scales. The theoretical framework, scale items, questionnaire development and validation are described in van de Mortel. $^{6}$

The questionnaire was translated into Greek by a bilingual infection control specialist, back-translated by an accredited company to ensure accuracy, and distributed to all final year nursing $(n=90)$ and medical $(n=60)$ students. The courses were four and six years in duration, respectively. Participation was voluntary, and responses were confidential. Ethics approval was obtained from the relevant Ethics Committees.

SPSS 16.0 for Mac was used to conduct analyses. The Cronbach's alpha values of the beliefs, practices and importance scales were $0.79,0.74$ and $0.71 . \mathrm{A} \mathrm{Chi}^{2}$ test was used to assess discipline differences in gender proportions. Descriptive statistics were calculated. Preliminary assumption testing was carried out prior to multivariate analysis. A one-way between-groups MANOVA was performed to investigate discipline differences in three domains (table 1). A Mann-Whitney test was used to examine the negatively skewed variable 'rate importance of $\mathrm{HH}$ from 1-10'. 


\section{Results}

The response rates of nursing and medical students were $85.6 \%$ and $36 \%$. Sixty-two percent of medical students and $82 \%$ of nursing students were female $\left(x^{2}=2.70(1) ; \mathrm{p}=\right.$ 0.100). Medical students were significantly older than nursing students ( $\bar{x} 25.20$ years \pm 0.33 vs. $23.62 \pm 0.53)(\mathrm{t}=-2.53(85,2) ; \mathrm{p}=0.013)$ and had spent longer on practicum $(\bar{x}$ 58.88 weeks \pm 9.68 vs. $36.39 \pm 1.11)(\mathrm{p}=0.035)$.

There were significant differences between disciplines on the combined dependent variables in each group; nursing students scored higher on all variables (table 1). Knowledge score, beliefs score, practices score, the frequency of $\mathrm{HH}$ assessment, the number of strategies used to teach $\mathrm{HH}$, students' perceptions of teaching effectiveness, and perceptions of the importance of $\mathrm{HH}$ in the curriculum, were significantly different when considered alone. 
Table 1. Differences in HH outcomes, education and perceptions by discipline.

\begin{tabular}{|c|c|c|c|c|c|}
\hline Variable & Discipline & Range (mean \pm s.e.m) & F value (df) & p value & Partial eta ${ }^{2}$ \\
\hline Outcomes & & & $14.40(3,94)$ & $0.000^{*}$ & $0.32(\mathrm{~L})$ \\
\hline \multirow[t]{2}{*}{ Knowledge } & Nursing & $3-11(8.84 \pm 0.19)$ & $35.16(1,96)$ & $0.000 *$ & $0.27(\mathrm{~L})$ \\
\hline & Medicine & $3-11(6.14 \pm 0.52)$ & & & \\
\hline \multirow[t]{2}{*}{ Beliefs (HBS) } & Nursing & $3.00-4.68(3.92 \pm 0.05)$ & $12.94(1,96)$ & $0.000^{*}$ & $0.12(\mathrm{M})$ \\
\hline & Medicine & $3.05-4.40(3.52 \pm 0.08)$ & & & \\
\hline \multirow[t]{2}{*}{ Practices (HHPI) } & Nursing & $4.00-5.00(4.75 \pm 0.03)$ & $4.63(1,96)$ & $0.034 *$ & $0.05(\mathrm{~S})$ \\
\hline & Medicine & $4.00-5.00(4.59 \pm 0.08)$ & & & \\
\hline Importance $\mathrm{HH}$ & Nursing & $7-10(9.60 \pm 0.08)$ & & 0.24 & \\
\hline $1-10$ & Medicine & $5-10(9.29 \pm 0.27)$ & & & \\
\hline Education & & & $13.85(2,94)$ & $0.000^{*}$ & $0.23(\mathrm{~L})$ \\
\hline $\mathrm{HH}$ assessment & Nursing & $1-15(7.13 \pm 0.42)$ & $23.58(1,95)$ & $0.000^{*}$ & $0.20(\mathrm{~L})$ \\
\hline frequency & Medicine & $0-11(2.86 \pm 0.74)$ & & & \\
\hline No. teaching & Nursing & $3-13(10.78 \pm 0.25)$ & $12.56(1,95)$ & $0.001 *$ & $0.12(\mathrm{M})$ \\
\hline strategies & Medicine & $0-13(8.19 \pm 1.04)$ & & & \\
\hline Perceptions & & & $8.13(2,94)$ & $0.000 *$ & $0.15(\mathrm{~L})$ \\
\hline Effectiveness of & Nursing & $0.46-3.38(2.92 \pm 0.08)$ & $12.30(1,95)$ & $0.001 *$ & $0.12(\mathrm{M})$ \\
\hline teaching & Medicine & $0-2.85(2.43 \pm 0.20)$ & & & \\
\hline strategies & & & & & \\
\hline Importance $\mathrm{HH}$ & Nursing & $2-5(3.89 \pm 0.07)$ & $6.88(1,95)$ & $0.004 *$ & $0.09(\mathrm{M})$ \\
\hline in curriculum & Medicine & $1-5(3.23 \pm 0.37)$ & & & \\
\hline (HIS) & & & & & \\
\hline
\end{tabular}

$\mathrm{L}=$ large; $\mathrm{M}=$ moderate $; \mathrm{S}=$ small effect size; $*$ significant at alpha $<0.05$

Nursing students found lectures, tutorials, textbooks and lecture notes significantly more effective than medical students (table 2). Teaching in the clinical setting occurred most frequently and was highly rated by both groups. Nursing and medical students 
were assessed on $\mathrm{HH}$ most frequently in the clinical setting $(2.12 \pm 0.18$ vs $1.57 \pm 0.37)$.

Nursing students were assessed significantly more often using written $(\bar{x} 1.86 \pm 0.15$ vs $0.19 \pm 0.15 ; \mathrm{t}=7.97(62.6) ; \mathrm{p}=0.000)$ and verbal assessment $(\bar{x} 1.42 \pm 0.16$ vs $0.43 \pm$ $0.16 ; \mathrm{t}=4.36(61.5) ; \mathrm{p}=0.000)$, and in the simulated clinical setting $(\bar{x} 1.71 \pm 0.15 \mathrm{vs}$ $0.67 \pm 0.23 ; \mathrm{t}=3.45(94) ; \mathrm{p}=0.001)$

Table 2. Percentage of students taught $\mathrm{HH}$ using a particular method and perceived effectiveness (mean \pm s.e.m). 1 = ineffective, 4 = highly effective.

\begin{tabular}{llll}
\hline Teaching method & Nursing & Medicine & Significance \\
\hline Lectures* & $90.9 \%(2.84 \pm 0.09)$ & $57.1 \%(1.67 \pm 0.26)$ & $\mathrm{t}=4.77(80): \mathrm{p}=0.000$ \\
Tutorials* & $96.1 \%(3.46 \pm 0.10)$ & $71.4 \%(2.27 \pm 0.27)$ & $\mathrm{t}=4.94(87) ; \mathrm{p}=0.000$ \\
Clinical setting & $97.4 \%(3.43 \pm 0.09)$ & $81.0 \%(3.18 \pm 0.25)$ & \\
Demonstration & $96.1 \%(3.24 \pm 0.10)$ & $76.2 \%(2.63 \pm 0.27)$ & \\
Practical laboratories & $93.5 \%(3.11 \pm 0.11)$ & $57.1 \%(3.17 \pm 0.17)$ & \\
Videos & $81.8 \%(2.75 \pm 0.10)$ & $47.6 \%(2.20 \pm 0.29)$ & \\
Textbooks* & $96.1 \%(2.76 \pm 0.10)$ & $81.0 \%(2.00 \pm 0.17)$ & $\mathrm{t}=3.38(89) ; \mathrm{p}=0.001$ \\
Lecture notes* & $89.6 \%(2.58 \pm 0.10)$ & $61.9 \%(1.69 \pm 0.24)$ & $\mathrm{t}=3.40(80) ; \mathrm{p}=0.001$ \\
Computer simulations & $35.1 \%(2.41 \pm 0.19)$ & $42.9 \%(2.22 \pm 0.28)$ & \\
Internet & $53.2 \%(2.32 \pm 0.13)$ & $47.6 \%(1.90 \pm 0.23)$ & \\
Research articles & $68.8 \%(2.74 \pm 0.12)$ & $57.1 \%(2.08 \pm 0.23)$ & \\
Published guidelines & $94.8 \%(2.96 \pm 0.13)$ & $71.4 \%(2.53 \pm 0.24)$ & \\
Posters & $84.4 \%(3.02 \pm 0.15)$ & $61.9 \%(2.85 \pm 0.32)$ & \\
Mean no. teaching strategies & $9.95( \pm 0.23)$ & $7.52( \pm 0.97)$ & \\
\hline *significant at alpha $<0.004$ & & & \\
\hline & & & \\
& & &
\end{tabular}

\section{Discussion}

Nursing students had greater HH knowledge, more positive beliefs and practices, and considered $\mathrm{HH}$ more important in their curriculum than medical students. Nursing 
students also received more $\mathrm{HH}$ education, rated their education as more effective and received more frequent $\mathrm{HH}$ assessment than medical students despite the longer duration of the medical degree. Instruction on $\mathrm{HH}$ was an elective topic for medical students; if they didn't enrol in the electives there was limited emphasis on $\mathrm{HH}$ in their course. As assessment often drives learning ${ }^{7}$ this may have impacted on medical students' knowledge and beliefs. Additionally, Calabro et al. ${ }^{8}$ demonstrated that a single educational infection control intervention for medical students did not result in longterm information retention, indicating that repeated exposure may be necessary for retention of key information.

The results suggest that an increased emphasis on $\mathrm{HH}$ education and assessment in the undergraduate curriculum may improve students' $\mathrm{HH}$ knowledge, beliefs and practices and make the practice culture more positive towards $\mathrm{HH}$. Contextualising $\mathrm{HH}$ education and assessment in the clinical setting may also improve learning outcomes as both student groups rated learning in the clinical environment as highly effective; the benefit of contextualisation in improving learning outcomes is supported by the literature. ${ }^{9}$

The study was limited by the small medical student sample (increasing the likelihood that the null hypothesis will be wrongly accepted), and the fact that only one higher education institution was sampled. Additionally, self-reported $\mathrm{HH}$ adherence can be substantially higher than observed adherence, ${ }^{2}$ although this is not always the case. ${ }^{10}$ The longer duration of medical students' training may have impaired recall of their $\mathrm{HH}$ education and assessment, although it also offered more opportunities for both. Finally, without manipulating variables of interest and observing the effects upon outcomes, it is not possible to state with certainty that one variable is influencing another. Other unmeasured factors may have influenced outcomes. 


\section{Recommendations}

Increasing the emphasis upon $\mathrm{HH}$ in the undergraduate curriculum through frequent $\mathrm{HH}$ education and assessment, particularly in the clinical setting, may improve students' HH knowledge, beliefs and practices and facilitate a positive practice culture towards $\mathrm{HH}$. Studies with a larger and more diverse sample are needed to confirm these results.

1. Centers for Disease Control. Guideline for hand hygiene in healthcare settings. MMWR 2002;51(RR-16): 1-48.

2. Snow M, White GL, Alder SC, Stanford, JB. Mentor's hand hygiene practices influence student's hand hygiene rates. Am J Infect Control 2006;34:18-24.

3. Sangkard, K. Assessment of nursing students' knowledge about infection control: implications for nursing education. Doctoral thesis: University of Iowa; 1991.

4. Karraffa J. Handwashing practices of university students: development of an instrument to test the Health Belief Model. Doctoral thesis: Southern Illinois University; 1989.

5. Mann CM, Wood A. How much do medical students know about infection control? J Hosp Infect 2006;64(4): 366-70.

6. van de Mortel, T.F. Development of an instrument to assess healthcare students' hand hygiene knowledge, beliefs and practices. Aust J Adv Nurs 2009;26(3): 9-16.

7. Gibbs G, Simpson C. Does your assessment support your students' learning? Learning and Teaching in Higher Education 2004-2005; Issue 1: 3-31.

8. Calabro K, Bright K, Kouzekanani K. Long-term effectiveness of infection control training among fourth-year medical students. Med Ed Online 2000; Retrieved March 10, 2009 from http://www.med-ed-online.org/res00009.htm 
9. Cordova DI, Lepper MR. Intrinsic motivation and the process of learning: Beneficial effects of contextualization, personalization, and choice. J Educ Psychol 1996; 88(4): 715-730.

10. Larson EL, Aiello AE, Carcillo JP. Assessing nurses hand hygiene practices by direct observation or self-report. J Nurs Meas 2004; 12(1): 77-85. 